\title{
Promoting effect of hepatitis $B$ virus on the expressoin of phospholipase A2 group IIA
}

\author{
Chengliang Zhu' ${ }^{1}$ Hui Song ${ }^{2}$, Bingzheng Shen ${ }^{1}$, Long Wu', Fang Liư ${ }^{3}$ and Xinghui Liu ${ }^{2 *}$
}

\begin{abstract}
Background: Hepatitis B virus (HBV) infection causes acute and chronic liver disease, ultimately leading to the development of liver cirrhosis (LC) and hepatocellular carcinoma (HCC). Phospholipase A2 group IIA (PLA2G2A) plays important roles in the development and progression of many tumors. Thus far, there have been no reports on the association between HBV and PLA2G2A. The present study investigated the effect of HBV infection on PLA2G2A expression and its application in the diagnosis of HBV-related diseases.

Methods: Serum levels of PLA2G2A in 308 HBV-infected patients and 185 healthy controls were measured using an enzyme-linked immunosorbent assay (ELISA). The difference in serum levels of PLA2G2A was analyzed among chronic hepatitis B (CHB), LC, and HCC patients. PLA2G2A mRNA and protein expression in HepG2 and HepG2.2.15 cells carrying the integrated HBV genome were measured using reverse transcription polymerase chain reaction (RT-PCR) and western blot assays. The HBV infectious clone pHBV1.3, the control plasmid pBlue-ks and PLA2G2A gene promoter were transfected into HepG2 and HepG2.2.15 cells. After transfection, the luciferase activity was measured in the cells. PLA2G2A mRNA and protein expression levels were examined using RT-PCR and western blot assays.

Results: The serum levels of PLA2G2A were $258.3 \pm 20.3 \mathrm{ng} / \mathrm{dl}$ in the healthy controls and $329.0 \pm 22.5 \mathrm{ng} / \mathrm{dl}$, $385.4 \pm 29.3 \mathrm{ng} / \mathrm{dl}$ and $459.2 \pm 38.6 \mathrm{ng} / \mathrm{dl}$ in the CHB, LC, and HCC patients, respectively. Statistical analyses revealed significantly higher serum levels of PLA2G2A in CHB, LC, and HCC patients than in the healthy controls $(P<0.05)$, and PLA2G2A levels were elevated in the order of HCC $>$ LC $>C H B$ group. High serum PLA2G2A levels in HCC patients were associated with a lower prevalence of lymph node metastasis and a lower TNM stage. HepG2.2.15 cells carrying the HBV genome expressed higher levels of PLA2G2A mRNA and protein than the HepG2 cells. In addition, HBV triggered PLA2G2A promoter activity and enhanced PLA2G2A mRNA and protein expression compared to the empty vector pBlue-ks.
\end{abstract}

Conclusion: HBV can upregulate the expression of PLA2G2A, and serum levels of PLA2G2A are associated with the progression of HBV-related diseases.

Keywords: Hepatitis B virus, Phospholipase A2 group IIA, Chronic hepatitis B, Liver cirrhosis, Hepatocellular carcinoma

\section{Background}

Hepatocellular carcinoma (HCC) is the third leading cause of cancer-related deaths. Hepatitis B virus (HBV) infection is a major factor for HCC development. Chronic hepatitis B (CHB) may lead to the development of liver cirrhosis (LC) and HCC. It is estimated that the

\footnotetext{
* Correspondence: syliuxh@163.com

${ }^{2}$ Department of Clinical Laboratory, Shanghai Gongli Hospital, the Second Military Medical University, Pudong New Area, Shanghai 200135, People's Republic of China

Full list of author information is available at the end of the article
}

risk of developing HCC is 200 times higher in chronic HBV-infected patients than in the general population without HBV infection [1-4]. However, the carcinogenic mechanism of HBV-related HCC is still poorly understood. It is generally considered that HBV infection is noncytopathic $[5,6]$. Instead, considerable evidence has shown an immune and inflammatory contribution to liver dysfunction, HBV infection activates a number of cellular genes including interleukin 27 (IL-27), IL-29, IL-8 and cyclooxygenase 2 [7-9]. In a previous research, 
we screened differentially expressed genes in HepG2.2.15 cells and HepG2 cells using gene chips [10]. Phospholipase A2 group IIA (PLA2G2A) was identified as a highly expressed gene in HepG2.2.15 cells (data not shown).

PLA2G2A is a secreted protein that is a member of the phospholipase A2 family. PLA2G2A is widely present in various mammalian tissues, such as the lung, thymus, liver, kidney, and prostate [11, 12]. PLA2G2A is closely associated with the inflammatory and immune response in the body [12, 13], and it also plays an important role in the development and progression of tumors $[14,15]$. The aim of the present study was to investigate the effect of HBV infection on PLA2G2A expression, its application in the diagnosis of HBV-related diseases, and the underlying molecular mechanism. The results will provide new insights as to the pathogenesis of $\mathrm{HBV}$ and for the diagnosis of HBV-related diseases.

\section{Methods}

\section{Study subjects}

In total, 308 patients clinically diagnosed with chronic HBV infection were recruited. According to the clinical, biochemical, serological, histopathological, abdominal ultrasound, computed tomography (CT) and magnetic resonance imaging (MRI) examination results, the patients were divided into three groups: $143 \mathrm{CHB}$ patients, including 81 men and 62 women, with a mean age of $43.2 \pm 16.7$ years, $86 \mathrm{LC}$ patients, including 48 men and 38 women, with a mean age of $50.5 \pm 18.5$ years, and 79 HCC patients, including 49 men and 30 women, with a mean age of $59.6 \pm 17.3$ years. All patients with diseases affecting the heart, brain, and kidneys (among various other vital organs) and those with other hepatotropic virus infections were excluded. The control group included 185 healthy examinees, including 105 men and 80 women, with a mean age of $48.6 \pm 20.1$ years.

\section{Cell culture and transfection}

HepG2 and HepG2.2.15 cells carrying the integrated HBV genome [16] were cultured in RPMI-1640 medium supplemented with $10 \%$ fetal bovine serum. The cultures were incubated in a cell incubator at $5 \% \mathrm{CO}_{2}$ and $37^{\circ} \mathrm{C}$. HepG2 cells were seeded into 6- or 24-well cell plates before transfection. When the cells reached approximately $80 \%$ confluency, $2 \mu \mathrm{g}$ of plasmid DNA and $2 \mu \mathrm{L}$ of Lipofectamine 2000 (Invitrogen, U.S.A) were diluted in $30 \mu \mathrm{L}$ of Dulbecco's Modified Eagle Medium (DMEM), or $4 \mu \mathrm{g}$ of plasmid DNA and $6 \mu \mathrm{L}$ of Lipofectamine 2000 reagent were diluted in $100 \mu \mathrm{L}$ of RPMI1640. The reactions were allowed to proceed at room temperature for $20 \mathrm{~min}$. The prepared transfection solution was added to the 24- or 6-well cell plates, and the cells were further incubated in a $\mathrm{CO}_{2}$ incubator.

\section{Reverse transcription polymerase chain reaction (RT-PCR)} assay

Total RNA was extracted from HepG2 and HepG2.2.15 cells using TRIzol reagent (Invitrogen, Carlsbad, CA, USA) [17]. The cDNA was synthesized using M-MLV reverse transcription. PCR amplification for PLA2G2A was verified using the following primers:

\section{PLA2G2A sense: 5' GCACTCAGTTATGGCTTC T3' and \\ PLA2G2A anti-sense: $5^{\prime}$ ATTGTAGGTCGTCTTGT TTC 3'. \\ $\beta$-actin was amplified as a control. The PCR products were checked using $1 \%$ agarose gel electrophoresis.}

\section{Luciferase assay}

After transfection, HepG2 and HepG2.2.15 cells were cultured for an additional $48 \mathrm{~h}$. The cell supernatants were removed, and the cells were harvested for lysis with a cell lysis buffer. After lysis, $10 \mu \mathrm{L}$ of cell lysate was mixed with $100 \mu \mathrm{L}$ of luciferase substrate, and the optical density was measured using a luminometer. Each sample was tested in triplicate.

\section{Western blot assay}

HepG2 cells were harvested and lysed, and then $30 \mu \mathrm{g}$ of protein from each sample was mixed with an equal volume of $5 \mathrm{X}$ loading buffer, which was then boiled at $100^{\circ} \mathrm{C}$ for $5 \mathrm{~min}$ and separated using 12\% SDS-PAGE gel electrophoresis. The proteins were then transferred to a nitrocellulose membrane and blocked with $5 \%$ skim milk for $2 \mathrm{~h}$. The membrane was incubated with the PLA2G2A monoclonal antibody (1:1000) for $2 \mathrm{~h}$. The membrane was washed with PBST three times and then incubated with anti-rabbit secondary antibody (Sigma, 1:5000) for $1 \mathrm{~h}$. After four washes with PBST, the membrane was subjected to color development using an electrochemiluminescence (ECL) detection system (Amersham Life Sciences).

\section{Enzyme-linked immunosorbent assay (ELISA)}

Approximately $2 \mathrm{~mL}$ of fasting venous blood was collected from each subject. Serum levels of PLA2G2A were measured using an ELISA kit (Cayman Chemical, AnnArbour, MI, USA) following the manufacturer's instructions. Each sample was tested in triplicate.

\section{Statistical analysis}

Statistical analyses were performed using the Statistical Package for the Social Sciences (SPSS) 16.0 statistical package. The data are expressed as the mean \pm standard deviation $(\overline{\mathrm{x}} \pm \mathrm{s})$, and a logistic regression analysis was performed adjusted for age. The differences among the healthy controls and the patients with $\mathrm{CHB}, \mathrm{LC}$ and 
HCC were assessed using one-way ANOVA, and a two tailed P-value $<0.05$ was considered statistically significant.

\section{Results}

Subjects

The demographic and clinical characteristics of the subjects are shown in Table 1 . There were no significant differences in gender and body mass index (BMI) among the 4 groups $(P>0.05)$. The subjects with more progressive disease tended to be older. The aspartate transaminase (AST) and alanine transaminase (ALT) levels were higher in the $\mathrm{CHB}, \mathrm{LC}$, and $\mathrm{HCC}$ patients compared with the healthy controls $(p<0.05)$, no significant difference existed among the CHB, LC, and HCC patients in terms of the HBV DNA $(P>0.05)$.

\section{Serum levels of PLA2G2A are elevated in HBV patients} Secreted PLA circulates in the blood stream and in virtually every tissue in mammals. We then measured the serum levels of PLA2G2A in healthy controls and in $\mathrm{CHB}, \mathrm{LC}$, and HCC patients using an ELISA. The results showed that the serum levels of PLA2G2A were $258.3 \pm$ $20.3 \mathrm{ng} / \mathrm{dl}, \quad 329.0 \pm 22.5 \mathrm{ng} / \mathrm{dl}, \quad 385.4 \pm 29.3 \mathrm{ng} / \mathrm{dl}, \quad$ and $459.2 \pm 38.6 \mathrm{ng} / \mathrm{dl}$ in the healthy controls, CHB patients, LC patients, and HCC patients, respectively. In the logistic regression analyses adjusted by age, we found that that compared with the healthy controls, the HBV patients had significantly higher serum levels of PLA2G2A $(P<0.05)$, Furthermore, among the various groups of patients, the serum levels of PLA2G2A consistently increased with the progression of HBV diseases which is in the order of $\mathrm{HCC}>\mathrm{LC}>\mathrm{CHB}$ patients (Fig. 1).

We further analyzed the relationship between the serum levels of PLA2G2A and the clinical characteristics in HCC patients. The results indicated that no significant associations were found between serum PLA2G2A

Table 1 Baseline characteristics of the subjects enrolled in the study

\begin{tabular}{lllll}
\hline Characteristic & $\begin{array}{l}\text { Healthy controls } \\
(n=185)\end{array}$ & $\begin{array}{l}\text { CHB patients } \\
(n=143)\end{array}$ & $\begin{array}{l}\text { LC patients } \\
(n=86)\end{array}$ & $\begin{array}{l}\text { HCC patients } \\
(n=79)\end{array}$ \\
\hline Age (years) & $48.6 \pm 20.1$ & $43.2 \pm 16.7$ & $50.5 \pm 18.5$ & $59.6 \pm 17.3$ \\
Gender (M/F) & $105 / 80$ & $81 / 62$ & $48 / 38$ & $49 / 30$ \\
BMI(kg/m²) & $26.3 \pm 1.7$ & $24.6 \pm 1.5$ & $25.2 \pm 1.8$ & $24.2 \pm 1.6$ \\
ALT(IU/I) & $<30$ & $183.5 \pm$ & $126.5 \pm 98.4$ & $65.7 \pm 43.2$ \\
AST(IU/I) & $<30$ & 105.7 & & \\
& & $1207.4 \pm$ & $113.4 \pm 86.5$ & $83.2 \pm 56.8$ \\
$\begin{array}{l}\text { HBV DNA } \\
\text { (Lg copies/ml) }\end{array}$ & 0 & $5.7 \pm 2.6$ & $5.5 \pm 2.2$ & $5.3 \pm 2.4$ \\
\hline
\end{tabular}

Abbreviations: $n$ number of the subjects, NS none sense, $M$ male, $F$ female, BMI body mass index, ALT alkanine aminotransferase, AST

aspartate aminotransferase levels and clinical factors including age and gender distribution $(P>0.05)$, whereas higher serum PLA2G2A levels were associated with less frequent lymph node metastasis and lower TNM stages (Table 2).

\section{HBV increases PLA2G2A mRNA and protein expression} HepG2.2.15 cells were stably transfected with the complete HBV genome, which expressed HBV RNA and viral proteins and produced virus-like particles [18]. To assess the effect of HBV on PLA2G2A expression, we analyzed PLA2G2A mRNA and protein expression in HepG2 and HepG2.2.15 cells using RT-PCR and western blot assays. The results showed that HepG2.2.15 cells expressed significantly higher levels of PLA2G2A mRNA and protein than the HepG2 cells (Fig. 2a and b).

PLA2G2A gene promoter activity is triggered by pHBV1.3 PHBV1.3 is an infectious clone of HBV. After transfection with pHBV1.3, HepG2 cells can synthesize and secrete HBV viral particles [9]. To investigate the molecular mechanism by which HBV regulates PLA2G2A expression, we co-transfected the HBV infectious clone pHBV1.3 and the PLA2G2A gene promoter pPLA2G2A-Luc into HepG2 cells, and pBlue-ks was transfected as a control. Additionally, pPLA2G2A-Luc was transfected into HepG2 and HepG2.2.15 cells respectively. The results of a luciferase activity assay showed that the PLA2G2A gene promoter activity was significantly enhanced in the HepG2 cells after transfection with pHBV1.3 $(692.5 \pm 28.8 \mathrm{RUL} / \mu \mathrm{g}$ protein, $P<0.05)$ compared with the control $(279.6 \pm 16.7$ $\mathrm{RUL} / \mu \mathrm{g}$ protein), and luciferase activity was much higher in HepG2.2.15 cells $(588.1 \pm 21.3 \mathrm{RUL} / \mu \mathrm{g}$ protein, $P<0.05)$ than in the HepG2 cells $(243.2 \pm 15.5$ $\mathrm{RUL} / \mu \mathrm{g}$ protein). This result indicated that HBV triggered PLA2G2A gene promoter activity (Fig. 3a and b).

\section{PHBV1.3 increases the PLA2G2A mRNA and protein expression}

We transfected pHBV1.3 into HepG2 cells and used an empty vector transfection with pBlue-ks as a control. Then, we analyzed the PLA2G2A mRNA and protein expression using RT-PCR and western blot assays, respectively. The results showed that compared with the control, the PLA2G2A mRNA and protein expression levels were increased in the HepG2 cells after transfection with pHBV1.3 (Fig. 4a and b).

\section{Discussion}

HBV is currently recognized as one of the main causes of HCC. The mechanism by which HBV infection leads to $\mathrm{HCC}$ is complex, involving both the host and viral factors [19]. For example, HBV can inactivate the tumor suppressor gene P53 in the body, 


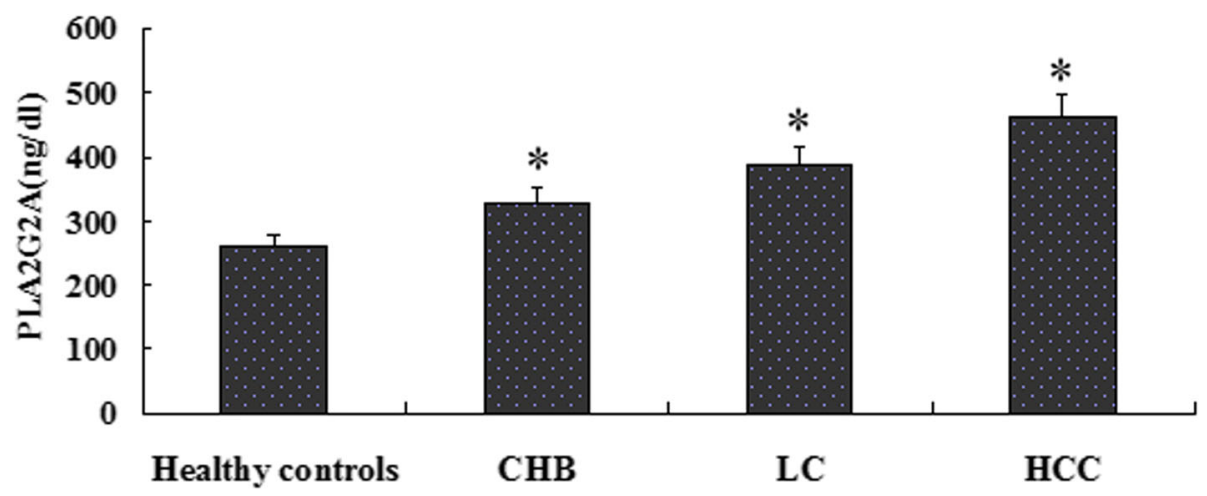

Fig. 1 Serum PLA2G2A levels in healthy controls and HBV patients. The serum PLA2G2A levels in the healthy controls and in CHB, LC, and HCC patients were measured using an ELISA. ${ }^{*} P<0.05$

leading to uncontrolled cell proliferation and endangering critical biological functions, such as DNA repair and control [20]. Additionally, HBV viral infection can induce a strong $\mathrm{T}$ cell immune response in the host. However, this immune response kills hepatocytes, which leads to inflammation and causes the regeneration of many hepatocytes, inducing a carcinogenic effect [21]. Moreover, HBV can regulate the expression of particular genes in the host, however, these genes participate in the development and progression of HCC [7]. Our previous research showed that $\mathrm{HBV}$ can increase the expression of collagen triple helix repeat containing-1(CTHRC1), which is a protein that plays a major role in promoting hepatocyte proliferation, migration, and invasion $[22,23]$.

In the present study, we found that HepG2.2.15 cells expressed significantly higher levels of PLA2G2A mRNA

Table 2 Association between PLA2G2A expression and clinical characteristics in HCC patients

\begin{tabular}{llll}
\hline Characteristics & Number & Serum PLA2G2A levels(ng/dl) & $P$ value \\
\hline Gender & & & \\
Male & 49 & $460.6 \pm 40.3$ & 0.472 \\
Female & 30 & $456.7 \pm 36.5$ & \\
Age (year) & & & 0.424 \\
$\geq 60$ & 53 & $458.5 \pm 37.4$ & \\
$<60$ & 26 & $462.2 \pm 41.7$ & 0.028 \\
Lymph node metastasis & & \\
Negative & 47 & $482.6 \pm 53.8$ & \\
$\quad$ Positive & 32 & $422.6 \pm 31.3$ & 0.018 \\
TNM stages & & & \\
I+ II & 28 & $491.7 \pm 55.3$ & \\
III + IV & 51 & $415.8 \pm 31.5$ & \\
\hline
\end{tabular}

Abbreviations: $n$ number of the subjects, TNM tumour node metastasis, PLA2G2A phospholipase A2 group IIA and protein than HepG2 cells. The serum levels of PLA2G2A in HBV patients were significantly elevated and associated with disease progression, lymph node metastasis and TNM stage. We further demonstrated that HBV increases PLA2G2A mRNA and protein expression by triggering the activity of its gene promoter.

HepG2.2.15 cells have a HBV stably integrated into its genome and are capable of producing HBV-like viruses. The cells are mostly arrested in the G1 phase. There is a reduction of filopodia, actin and ezrin in HepG2.2.15, which makes them less invasive after implantation in nude mice than the HepG2 parental line, and the HepG2.2.15 implanted cells caused liver necrosis, fatty liver, high cholesterol, degenerative changes, and neutrophil infiltration [24]. This study found that HepG2.2.15 cells had significantly increased PLA2G2A levels compared with HepG2 cells.

PLA2G2A expression was elevated in primary gastric, colon, and prostrate tumors and $\beta$-catenin-dependent Wnt signaling is a major upstream regulator of PLA2G2A expression [25]. Hepatitis B virus $X$ (HBX) protein upregulates $\beta$-catenin and the $\mathrm{Wnt} / \beta$-catenin pathway is frequently activated in HBV-induced HCC $[19,26]$, which suggests that HBV might upregulate the expression of PLA2G2A via the Wnt signaling pathways.

Recent studies showed that PLA2G2A is closely associated with the development and progression of particular tumors $[15,27-29]$. PLA2G2A can stimulate tumor cell growth, whereas the product of PLA2G2A, arachidonic acid, leads to prostate tumor cell proliferation and facilitates tumor angiogenesis and metastasis. However, PLA2G2A expression was decreased in metastatic and late-stage tumors and is associated with prolonged survival and less frequent metastasis in gastricadenocarcinoma [25]. In the present study, we found that elevated PLA2G2A expression was associated with less frequent lymph 


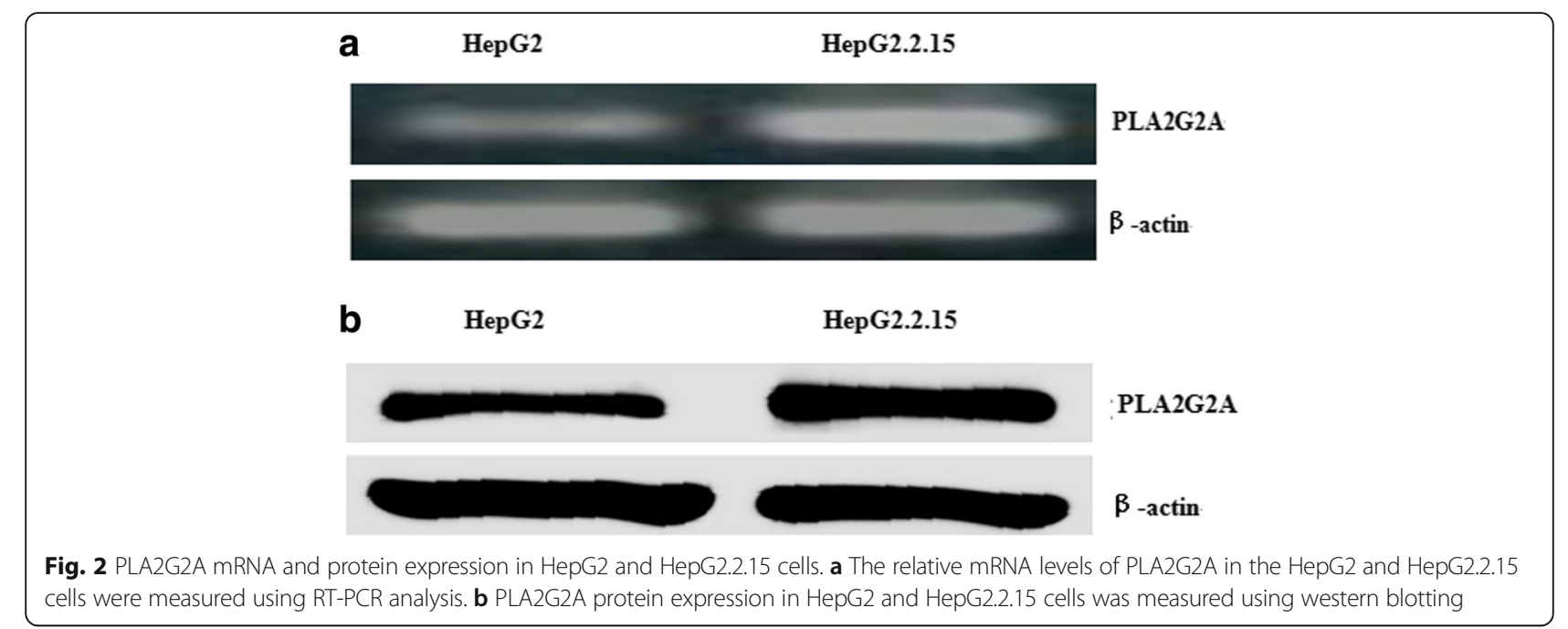

node metastasis and lower TNM stages. However, this study has certain limitations such as the small sample size in the patient subgroups, and the evaluation of the correlation of serum PLA2G2A levels with the prognosis of $\mathrm{HCC}$ patients needs to be evaluated. In addition, the detailed molecular mechanism of how
HBV induces the promoter activity of PLA2G2A needs further investigation.

\section{Conclusions}

Taken together, for the first time, we demonstrated the dynamic changes in PLA2G2A expression in the
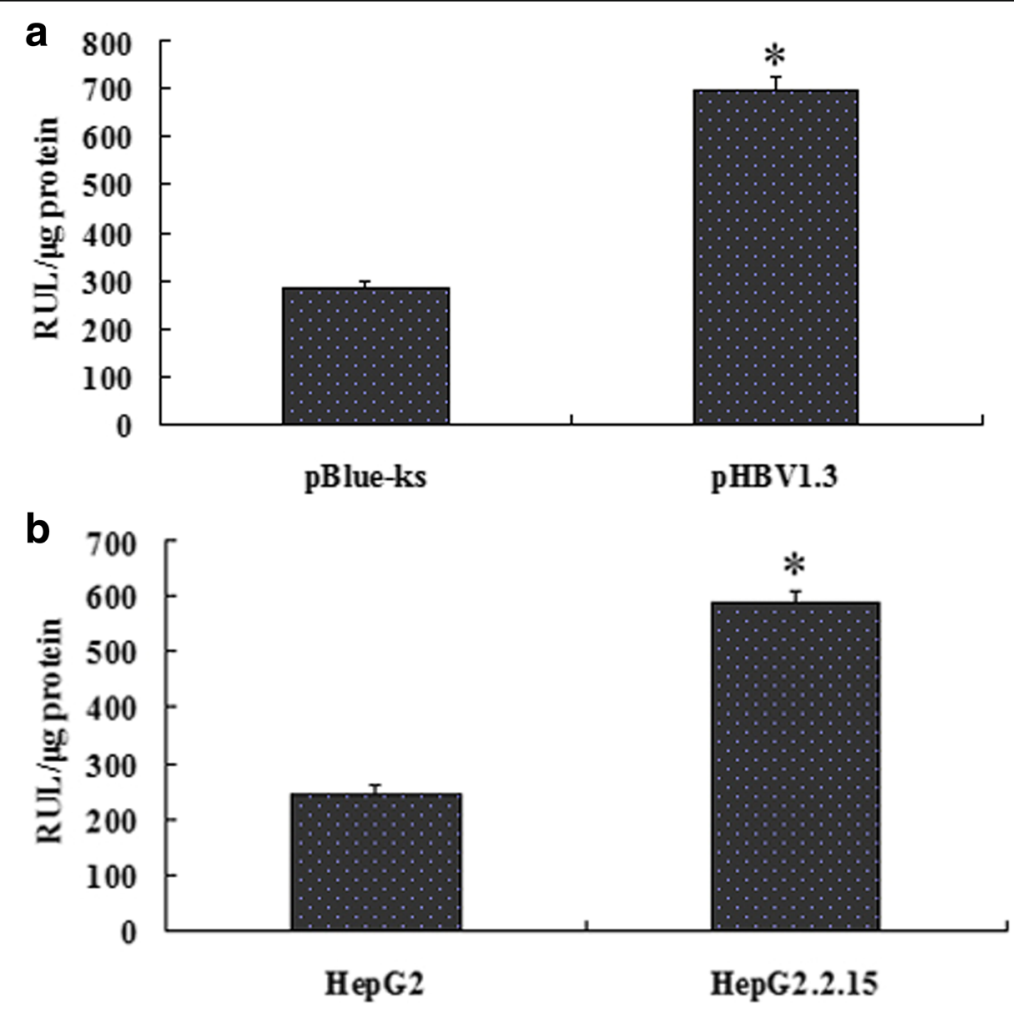

Fig. 3 Effect of HBV on the activity of the PLA2G2A promoter. a HepG2 cells were co-transfected with pHBV1.3/pBlue-ks and the PLA2G2A promoter pPLA2G2A-Luc plasmid, and then luciferase activity was measured. b HepG2 and HepG2.2.15 cells were transfected with PLA2G2A promoter pPLA2G2A-Luc plasmid, and then luciferase activity was measured. ${ }^{*} P<0.05$ 


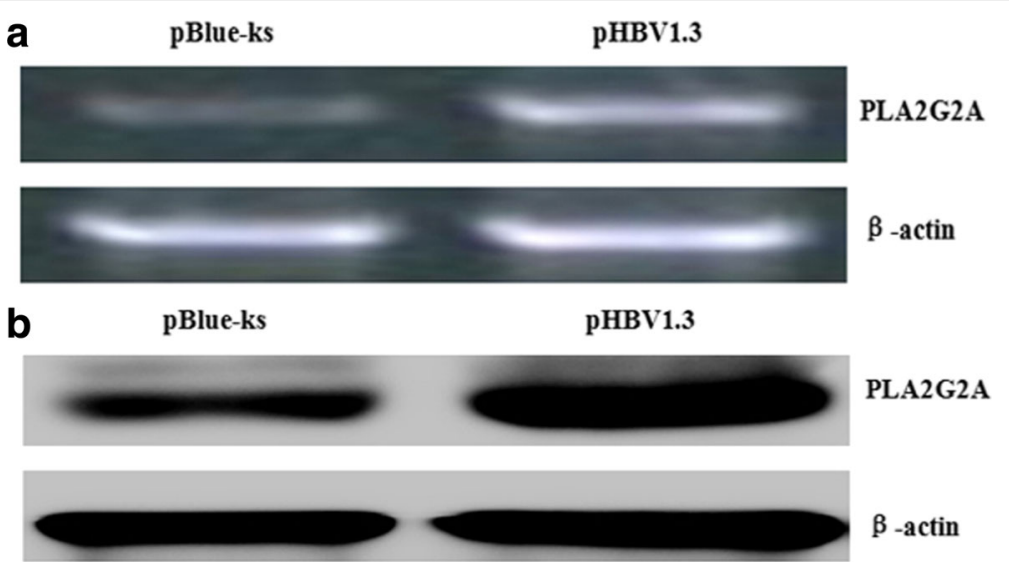

Fig. 4 Effect of pHBV1.3 on PLA2G2A mRNA and protein expression. a Effects of pHBV1.3 on the expression of PLA2G2A mRNA. HepG2 cells were transfected with pHBV1.3 or pBlue-ks, and then $48 \mathrm{~h}$ after transfection, PLA2G2A mRNA was measured by RT-PCR analysis. b Effects of pHBV1.3 on the expression of PLA2G2A protein. HepG2 cells were transfected with pHBV1.3 or pBlue-ks, and then $48 \mathrm{~h}$ after transfection, PLA2G2A protein was measured using western blotting

progression of $\mathrm{HBV}$ infection ranging from $\mathrm{CHB}, \mathrm{LC}$ to HCC. Therefore, measuring the serum levels of PLA2G2A in HBV patients may provide a new biomarker for the diagnosis of progressive liver diseases during chronic HBV infection.

\section{Acknowledgements}

The authors are grateful to all the volunteers for participating in the study.

\section{Funding}

This study was supported by the key discipline construction project of Pudong Health Bureau of Shanghai(PWZx2014-03), Science and Technology Development Fund of Shanghai Pudong New Area(PKJ2016-Y56),the National Science Foundation of China $(81672079,81302133)$, and the Open Research Program of the State Key Laboratory of Virology of China (no. 2015KF002, 2015KF007, and 2016KF003).

\section{Availability of data and materials}

The dataset supporting the conclusions of this article is included within the article.

\section{Authors' contributions}

CLZ participated in the cell culture, transfection, RT-PCR and western blot assay. BZS participated in the sample collection and conducted the ELISA HS and FL performed the luciferase activity assays and statistical analysis. LW participated in the analyzed of the relationship between the serum levels of PLA2G2A and the clinical characteristics in the HCC patients. XHL participated in the design of the study. All authors read and approved the final manuscript.

\section{Competing interests}

The authors declare that they have no competing interests.

\section{Consent for publication}

Not applicable.

\section{Ethics approval and consent to participate}

This work was approved by the Ethics Committee of Renmin hospital of Wuhan University. Written informed consent was obtained from all the participating individuals.

\section{Author details}

'Department of Clinical Laboratory, Renmin Hospital of Wuhan University, Wuhan, Hubei 430060, People's Republic of China. ${ }^{2}$ Department of Clinical Laboratory, Shanghai Gongli Hospital, the Second Military Medical University, Pudong New Area, Shanghai 200135, People's Republic of China. ${ }^{3}$ The State Key Laboratory of Virology, College of Life Sciences, Wuhan University, Wuhan, Hubei 430072, People's Republic of China.

Received: 17 August 2016 Accepted: 27 December 2016 Published online: 11 January 2017

\section{References}

1. Papatheodoridis GV, Chan HL, Hansen BE, Janssen HL, Lampertico P. Risk of hepatocellular carcinoma in chronic hepatitis B: assessment and modification with current antiviral therapy. J Hepatol. 2015;62:956-67.

2. Yamada R, Hiramatsu N, Oze T, Morishita N, Harada N, Yakushijin T, lio S, Doi Y, Yamada A, Kaneko A, et al. Impact of alpha-fetoprotein on hepatocellular carcinoma development during entecavir treatment of chronic hepatitis B virus infection. J Gastroenterol. 2015;50:785-94.

3. Wang X, Wang N, Cheung F, Lao L, Li C, Feng Y. Chinese medicines for prevention and treatment of human hepatocellular carcinoma: current progress on pharmacological actions and mechanisms. J Integr Med. 2015;13:142-64.

4. Sunbul M. Hepatitis B virus genotypes: global distribution and clinical importance. World J Gastroenterol. 2014;20:5427-34.

5. El-Serag HB. Epidemiology of viral hepatitis and hepatocellular carcinoma. Gastroenterology. 2012;142:1264-73. e1261.

6. Norton PA, Gong Q, Mehta AS, Lu X, Block TM. Hepatitis B virus-mediated changes of apolipoprotein mRNA abundance in cultured hepatoma cells. J Virol. 2003;77:5503-6.

7. Jiang W, Zheng L, Yang Q, Huang Z, Wang X. Investigation into the effect of hepatitis B virus on apoliprotein A1 expression and its mechanism. Lipids Health Dis. 2014;13:130.

8. Yu Y, Gong R, Mu Y, Chen Y, Zhu C, Sun Z, Chen M, Liu Y, Zhu Y, Wu J. Hepatitis $B$ virus induces a novel inflammation network involving three inflammatory factors, IL-29, LL-8, and cyclooxygenase-2. J Immunol. 2011;187:4844-60.

9. Zhu C, Zhang R, Liu L, Rasool ST, Mu Y, Sun W, Hao Q, Liu F, Zhu Y, Wu J. Hepatitis B virus enhances interleukin-27 expression both in vivo and in vitro. Clin Immunol. 2009;131:92-7.

10. Wang FB, Zhu CL, Liu X, Gao GS. HBV inhibits apoB production via the suppression of MTP expression. Lipids Health Dis. 2011;10:207.

11. Belinsky GS, Rajan TV, Saria EA, Giardina C, Rosenberg DW. Expression of secretory phospholipase A2 in colon tumor cells potentiates tumor growth. Mol Carcinog. 2007;46:106-16. 
12. Oleksowicz L, Liu Y, Bracken RB, Gaitonde K, Burke B, Succop P, Levin L, Dong Z, Lu S. Secretory phospholipase A2-lla is a target gene of the HER/ HER2-elicited pathway and a potential plasma biomarker for poor prognosis of prostate cancer. Prostate. 2012;72:1140-9.

13. Wu F, Chakravarti S. Differential expression of inflammatory and fibrogenic genes and their regulation by NF-kappaB inhibition in a mouse model of chronic colitis. J Immunol. 2007;179:6988-7000.

14. Buhmeida A, Bendardaf R, Hilska M, Laine J, Collan Y, Laato M, Syrjanen K, Pyrhonen S. PLA2 (group IIA phospholipase A2) as a prognostic determinant in stage II colorectal carcinoma. Ann Oncol. 2009;20:1230-5.

15. Menschikowski M, Hagelgans A, Schuler U, Froeschke S, Rosner A, Siegert G. Plasma levels of phospholipase A2-IIA in patients with different types of malignancies: prognosis and association with inflammatory and coagulation biomarkers. Pathol Oncol Res. 2013;19:839-46.

16. Yue X, Yang F, Yang Y, Mu Y, Sun W, Li W, Xu D, Wu J, Zhu Y. Induction of cyclooxygenase-2 expression by hepatitis $B$ virus depends on demethylation-associated recruitment of transcription factors to the promoter. Virol J. 2011;8:118.

17. Zhang YH, Wang Y, Yusufali AH, Ashby F, Zhang D, Yin ZF, Aslanidi GV, Srivastava A, Ling CQ, Ling C. Cytotoxic genes from traditional Chinese medicine inhibit tumor growth both in vitro and in vivo. J Integr Med. 2014:12:483-94.

18. Wang Y, Hao J, Liu X, Wang H, Zeng X, Yang J, Li L, Kuang X, Zhang T. The mechanism of apoliprotein A1 down-regulated by Hepatitis B virus. Lipids Health Dis. 2016;15:64.

19. Levrero M, Zucman-Rossi J. Mechanisms of HBV-induced hepatocellular carcinoma. J Hepatol. 2016;64:S84-S101.

20. Hussain SP, Schwank J, Staib F, Wang XW, Harris CC. TP53 mutations and hepatocellular carcinoma: insights into the etiology and pathogenesis of liver cancer. Oncogene. 2007;26:2166-76.

21. Chen L, Zhang Q, Chang W, Du Y, Zhang H, Cao G. Viral and host inflammation-related factors that can predict the prognosis of hepatocellular carcinoma. Eur J Cancer. 2012;48:1977-87.

22. Bai L, Zhang W, Tan L, Yang H, Ge M, Zhu C, Zhang R, Cao Y, Chen J, Luo Z, et al. Hepatitis $B$ virus hijacks $C T H R C 1$ to evade host immunity and maintain replication. J Mol Cell Biol. 2015;7:543-56.

23. Zhang R, Cao Y, Bai L, Zhu C, Li R, He H, Liu Y, Wu K, Liu F, Wu J. The collagen triple helix repeat containing 1 facilitates hepatitis $B$ virusassociated hepatocellular carcinoma progression by regulating multiple cellular factors and signal cascades. Mol Carcinog. 2015;54:1554-66.

24. Zhao R, Wang TZ, Kong D, Zhang L, Meng HX, Jiang Y, Wu YQ, Yu ZX, Jin XM. Hepatoma cell line HepG2.2.15 demonstrates distinct biological features compared with parental HepG2. World J Gastroenterol. 2011;17:1152-9.

25. Ganesan K, Ivanova T, Wu Y, Rajasegaran V, Wu J, Lee MH, Yu K, Rha SY, Chung $\mathrm{HC}$, Ylstra B, et al. Inhibition of gastric cancer invasion and metastasis by PLA2G2A, a novel beta-catenin/TCF target gene. Cancer Res. 2008;68:4277-86.

26. Srisuttee R, Koh SS, Kim SJ, Malilas W, Boonying W, Cho IR, Jhun BH, Ito M, Horio $Y$, Seto E, et al. Hepatitis B virus X (HBX) protein upregulates betacatenin in a human hepatic cell line by sequestering SIRT1 deacetylase. Oncol Rep. 2012;28:276-82.

27. Leung SY, Chen X, Chu KM, Yuen ST, Mathy J, Ji J, Chan AS, Li R, Law S, Troyanskaya OG, et al. Phospholipase A2 group IIA expression in gastric adenocarcinoma is associated with prolonged survival and less frequent metastasis. Proc Natl Acad Sci U S A. 2002;99:16203-8.

28. Wang M, Hao FY, Wang JG, Xiao W. Group lla secretory phospholipase A2 (sPLA2lla) and progression in patients with lung cancer. Eur Rev Med Pharmacol Sci. 2014;18:2648-54.

29. Wang X, Huang CJ, Yu GZ, Wang JJ, Wang R, Li YM, Wu Q. Expression of group IIA phospholipase A2 is an independent predictor of favorable outcome for patients with gastric cancer. Hum Pathol. 2013;44:2020-7.

\section{Submit your next manuscript to BioMed Central and we will help you at every step:}

- We accept pre-submission inquiries

- Our selector tool helps you to find the most relevant journal

- We provide round the clock customer support

- Convenient online submission

- Thorough peer review

- Inclusion in PubMed and all major indexing services

- Maximum visibility for your research

Submit your manuscript at www.biomedcentral.com/submit
Biomed Central 